\title{
PTEN mutation, loss of heterozygosity, promoter methylation and expression in colorectal carcinoma: Two hits on the gene?
}

\author{
MAJA HÜHNS $^{1 *}$, TAREQ SALEM $^{1 *}$, BJÖRN SCHNEIDER $^{1}$, MATHIAS KROHN $^{2}$, \\ MICHAEL LINNEBACHER ${ }^{2}$ and FRIEDRICH PRALL ${ }^{1}$ \\ ${ }^{1}$ Institute of Pathology and ${ }^{2}$ Department of Surgery, Rostock University, D-18055 Rostock, Germany
}

Received December 16, 2013; Accepted February 3, 2014

DOI: 10.3892/or.2014.3097

\begin{abstract}
The phosphatase and tensin homologue (PTEN) gene is considered to be a tumour-suppressor gene in various types of cancer, colorectal carcinoma among them. According to the 'two-hit' tumour-suppressor gene concept, inactivation occurs by any combination of the following three pathogenetic processes: mutation, loss of one allele [i.e. loss of heterozygosity $(\mathrm{LOH})]$ or promoter methylation. To determine the frequencies of PTEN tumour-suppressor gene features in colorectal carcinoma, we used DNA from colorectal carcinoma xenografts/ primary tumour cell lines $(\mathrm{N}=22)$ or neoplastic glands isolated by laser-capture microdissection $(\mathrm{N}=20)$. Sequencing exons 1-9 of the gene revealed a total of 8 somatic mutations in 5 tumours ( 3 with high-degree microsatellite instability). In 1 tumour, a truncating mutation of one allele was combined with two missense mutations of the other allele. Polymorphic microsatellite marker analyses (D10S5412, D10S579 and D10S1765) showed complete loss of one allele (i.e. LOH sensu stricto) in 3 tumours, but combined LOH and mutation was found only once. Promoter methylation, tested by MethyLight technology, was found in only 1 of the tumours, not combined with mutation or LOH. In contrast, by immunohistochemistry ( $\mathrm{mAb}$ $6 \mathrm{H} 2.1$ ), reduction or even loss of PTEN expression was found in 18 tumours. Taken together, PTEN downregulation is a fairly frequent event in colorectal carcinoma, but this apparently is not usually caused by two hits on the gene.
\end{abstract}

\section{Introduction}

The phosphatase and tensin homologue (PTEN) gene is registered with a mutation rate of $12.4 \%$ for colorectal cancer in the COSMIC database (http://cancer.sanger.ac.uk/cancer-

Correspondence to: Professor Friedrich Prall, Institute of Pathology, Rostock University, Strempelstrasse 14, D-18055 Rostock, Germany

E-mail: friedrich.prall@med.uni-rostock.de

${ }^{*}$ Contributed equally

Key words: phosphatase and tensin homologue, colorectal carcinoma, loss of heterozygosity, promoter methylation genome/ projects/cosmic/). This places the PTEN gene among the 'hills' of the colorectal cancer genomic landscape (1). The mutations are distributed fairly evenly over the gene's 9 exons which by recent concepts is a key molecular feature of tumoursuppressor genes. In addition, losses of genomic material at its locus 10p23.3 or epigenetic silencing of the gene promoter are observed. Considering that the PTEN protein participates in cell growth control by counteracting Akt signaling in the cytoplasm and activity of the mitogen-activated protein kinase in the nucleus (2), there seems to be a strong case for PTEN as a tumour-suppressor gene. In fact, PTEN features in the literature as a tumour-suppressor gene ever since its first description (3).

For some types of cancers, most notably endometrial adenocarcinoma, prostate cancer, gliomas and malignant melanoma, the evidence for PTEN as a tumour-suppressor gene is strong indeed. However, in colorectal carcinoma this may not be quite so. First, PTEN gene mutations are particularly frequent among the $\sim 15 \%$ of colorectal carcinomas driven by microsatellite instability (4), whereas the classical tumoursuppressor gene mechanism that combines mutation of one allele and loss of the other allele would rather be expected to apply to colorectal carcinomas driven by chromosomal instability (CIN). Second, published studies that have addressed allelic loss usually employed microsatellite marker analyses using DNA from tumour tissue homogenates, i.e. mixtures of the neoplastic cells and the normal stroma. As a limitation of this technique, 'loss of heterozygosity' (LOH) in most cases can only be scored according to an arbitrary cut-off applied to the tumour/normal ratios of the PCR products visualised in electropherograms or gel-autoradiographs. A wise note of caution concerning this type of study has been made by Devilee et al (5).

PTEN may be a colorectal carcinoma tumour-suppressor gene by a less rigorous definition, i.e. it may be one of the so-called 'epi-driver genes' (6). In this type of tumoursuppressor genes, loss of expression (and function) occurs e.g. by promoter methylation (epigenetic gene silencing). PTEN promoter methylation has been reported in several types of cancers, colorectal carcinoma among them (7).

In the present study, we investigated the mutational status, $\mathrm{LOH}$, promoter methylation, and, by immunohistochemistry, expression of the PTEN gene in a series of 42 colorectal carcinomas for a synoptic view on all molecular processes that by 
recent concepts would identify PTEN as a tumour-suppressor gene in this type of cancer. Importantly, we used tumour tissue from low-passage xenotransplants or neoplastic glands isolated by laser-capture microdissection for the LOH studies.

\section{Materials and methods}

Colorectal carcinoma specimens. In the present study, we used colorectal carcinoma specimens collected at Rostock University as part of and according to the guidelines and procedures of the 'Norddeutsche Tumorbank' as has been described in detail in a previous publication (8). Briefly, surgical resection specimens from patients with biopsy proven colorectal carcinoma (adenocarcinoma not otherwise specified) were received fresh from the operating theatre; patients had not received chemotherapy or radiation prior to surgery. Small cubes $(\sim 3 \times 3 \times 3 \mathrm{~mm})$ were dissected from vital parts of the tumours by the senior author, snap-frozen in liquid nitrogen and stored at $-80^{\circ} \mathrm{C}$; a strip of normal mucosa was taken from near the resection margins. The present series consisted of 22 cases for which subcutaneous xenotransplantation into athymic nude mice was successful or for which a primary colorectal carcinoma cell line was generated (19 and 3, respectively; subset 1), the techniques used have been previously described (9); 20 additional tumours were selected from the tumour bank for which xenografting had not been attempted or that had failed to grow as xenotransplants (subset 2). The animal studies were registered officially and received formal ethical approval (ref. LALLF M-V/TSD/7221.3-1.1-071/10). After overnight-fixation in buffered aqueous formaldehyde solution $(4 \% \mathrm{w} / \mathrm{v})$ the remaining major portions of the surgical specimens were dissected, slices of the tumours blocked in paraffin, and a surgical pathology report was issued that typed, graded and staged the tumours according to the TNM system of the UICC (7th edition). Information on clinical staging and the patient's personal and family history (as recorded on firstcontact interviews) were available from the clinical charts. Prior written informed consent was obtained from all patients, and all procedures were approved by the Ethics Committee of Rostock University (ref. II HV 43/2004).

Molecular studies for classification of the tumours. Molecular classification of the tumours was carried out according to the results of molecular studies as previously published (10). Briefly, DNA was extracted from the tumour xenografts (passages 1-3) (subset 1); or from the tumour specimens stored in the tumour bank (subset 2) in which case cryosections were taken and examined histologically to ascertain that the tumour was well represented.

Microsatellite instability was assayed by the Bethesda panel and CAT26 as an additional quasi-monomorphic mononucleotide marker. Tumours were classified as high-degree microsatellite instable (MSI-H) if positive with three or more of the Bethesda markers; CAT26 was positive in all of these cases.

Methylations were assessed by quantitative real-time PCR using MethyLight technology as published by Ogino et al (11) using the following marker panel: CACNA1G, CDKN2A, CRABPB1, MLH1 and NEUROG. COL2A1 was used for normalization of the input DNA. The EpiTect Bilsulfite kit
(Qiagen, Hilden, Germany) was used for bisulfite treatment. A locus was classified as methylated when the percentage of methylated reference exceeded 4 (PMR $>4$ ).

K-Ras codon 12/13 and B-raf V600E mutations were tested as previously described (10).

\section{Molecular analyses of PTEN}

PTEN gene sequencing. PTEN gene exons 1-9 were amplified by PCR from genomic DNA extracted from xenotransplants or from the tumour tissues retrieved from the tumour bank. PCR primers and amplification conditions are documented in Table I. PCR products were purified with alkaline phosphatase (Fermentas, Schwerte, Germany) and Exonuclease I (Fermentas). Subsequently, the sequencing reactions were performed using the BigDye Terminator v3.1 cycle sequencing kit (Applied Biosystems, Darmstadt, Germany) with each pair of forward and reverse primers. The sequence data were compared with the published PTEN sequence (Genbank GI: 4240386) using SeqScape ${ }^{\circledR}$ Software v2.7 (Applied Biosystems) and Chromas Lite (Technelysium Pty. Ltd., South Bristol, Australia). Sequencing of non-tumour DNA (from normal mucosa) was used to ascertain that PTEN mutations found in the tumours actually were somatic. Mutations were confirmed by independent repeat analyses. Furthermore, to determine if the mutations were monoallelic or biallelic for positive cases from subset 2 , sequencing was repeated with DNA from neoplastic glands that were isolated from cryostat sections using a PALM laser-capture device (Carl Zeiss, Göttingen, Germany).

PTEN allelotyping. Allelotyping of the PTEN gene was carried out with DNA extracted from the tumour xenografts/ primary cell lines (subset 1), or with DNA obtained by lasercapture microdissection of the neoplastic glands (subset 2). Tumour and non-tumour DNA was amplified by PCR with published polymorphic microsatellite markers located close to the PTEN gene (D10S541, D10S579 and D10S1765) $(12,13)$. Each sense primer was fluorescence labelled with FAM at the $5^{\prime}$ end. PCR was carried out as follows. Reactions were started at $95^{\circ} \mathrm{C}$ for $10 \mathrm{~min}$, and this was followed by 30 cycles at $94^{\circ} \mathrm{C}$ for $30 \mathrm{sec}, 60^{\circ} \mathrm{C}$ for $30 \mathrm{sec}$ and $72^{\circ} \mathrm{C}$ for $45 \mathrm{sec}$ and finally a $10-\mathrm{min}$ extension at $72^{\circ} \mathrm{C}$. PCR products were separated by capillary gel electrophoresis and detected on an automated ABI 3500 Genetic Analyzer (Applied Biosystems). Fragment length and fluorescence intensity were evaluated by GeneMapper software. The GeneScan ${ }^{\mathrm{TM}}-500 \mathrm{LIZ}^{\mathrm{TM}}$ size marker (Applied Biosystems) served as an internal standard. A tumour was considered to have PTEN allelic imbalance (AI) if the tumour to normal ratios were $\leq 0.5$ or $\geq 2.0$. Only in the case of a complete loss of one allele, was the case considered positive for $\mathrm{LOH}$ of the PTEN gene.

PTEN gene promoter methylation assays. A primer/probe combination specific for the methylated PTEN promoter sequence was used (forward, 5'-GGTGATGTGGCGGGATT TT-3' and reverse, 5'-CGCCTCACAACGACTCAAC-3'; probe: 5'-6FAM-TGCGGTAGGATACGCGTTCGGC-TM R-3') with the SensiFast Probe kit (Bioline, Luckenwalde, Germany). CpG Methylase (SssI)-treated DNA served as a calibrator, since it is considered to be fully methylated. The 
Table I. Primers and PCR conditions for PTEN sequencing.

\begin{tabular}{|c|c|c|c|}
\hline Exon & Primer sequences & $\mathrm{AT}\left({ }^{\circ} \mathrm{C}\right)$ & Product size (bp) \\
\hline 1 & $\begin{array}{l}\text { 5'-CAGCCGTTCGGAGGATTA-3' } \\
\text { 5'-ATATGACCTAGCAACCTGACCA-3' }\end{array}$ & 60 & 484 \\
\hline 2 & $\begin{array}{l}\text { 5'-GTACTTTAGTTCTGTGATGTATAAACCGT-3' } \\
\text { 5'-CTGAAGTCCATTA-3' }\end{array}$ & 60 & 509 \\
\hline 3 & $\begin{array}{l}\text { 5'-ATGTTTGTGAGGGTCGAATG-3' } \\
\text { 5'-GGACTTCTTGACTTAATCGGTTTAG-3' }\end{array}$ & 60 & 726 \\
\hline 4 & $\begin{array}{l}\text { 5'-TGAAAAAGGTGATCGTTGGC-3' } \\
\text { 5'-ATTGTTATGACAGTAAGATACAGTCTATCG-3' }\end{array}$ & 60 & 657 \\
\hline 5 & $\begin{array}{l}\text { 5'-TTCTGAGGTTATCTTTTTACCACAG-3' } \\
\text { 5'TCCAGGAAGAGGAAAGGAAAA--3' }\end{array}$ & 60 & 303 \\
\hline 6 & $\begin{array}{l}\text { 5'-AATGTATATATGTTCTTAAATGGCTACGA-3' } \\
\text { 5'-TCATAAATATAATTTGGCTTCGACTAC-3' }\end{array}$ & 60 & 484 \\
\hline 7 & $\begin{array}{l}\text { 5'-TGACAGTTTGACAGTTAAAGG-3' } \\
\text { 5'-GATATTTCTCCCAATGTAAAGT-3' }\end{array}$ & 55 & 262 \\
\hline 8 & $\begin{array}{l}\text { 5'-GCAACAGATAACTCAGATTGCC-3' } \\
\text { 5'-TCAAGCAAGTTCTTCATCAGC-3' }\end{array}$ & 54 & 514 \\
\hline 9 & $\begin{array}{l}\text { 5'-TGTTCATCTGCAAAATGGAAT-3' } \\
\text { 5'-CAAGTGTCAAAACCCTGTGG-3' }\end{array}$ & 54 & 469 \\
\hline
\end{tabular}

AT, annealing temperature; PTEN, phosphatase and tensin homologue.

collagenase gene 2A1 (COL2A1) was used as endogenous control (forward, 5'-TCTAACAATTATAAACTCCAACCAC CAA-3' and reverse, 5'-GGGAAGATGGGATAGAAGGGAA TAT-3'; probe, 5'-6FAM-CCTTCATTCTAACCCAATACCT ATCCCACCTCTAAA-TMR-3'). Quantitative PCR was performed using the StepOne Plus System (Applied Biosystems). The PMR value was calculated by dividing the gene of interest/COL2A1 ratio of the sample by the gene of interest/COL2A1 ratio of the SssI-treated DNA, and multiplying by 100 . Samples with a PMR value $>4$ were considered as methylated. All reactions were performed in triplicates.

PTEN immunohistochemistry. A paraffin block representing a full cross-section through the tumour was selected from the archived material for each case. Anti-PTEN monoclonal antibody $6 \mathrm{H} 2.1$ was applied at a titre of $1: 100$ to $4-\mu \mathrm{m}$ sections after heat-induced antigen retrieval and stained on an autoimmunostainer (both from Dako, Glostrup, Denmark) according to the manufacturer's standard procedures. Mab $6 \mathrm{H} 2.1$ has been previously well characterised for its specificity (13); furthermore, strong nuclear and cytoplasmic immunostaining of endothelia provides a convenient internal control of the immunoreactions and gives a standard to compare to when scoring tumour tissues. In the present study, nuclear and cytoplasmic immunostaining was scored as strong (score 2) when comparable to the staining of endothelia, as moderate (score 1) when observed to be unequivocally present but weaker than endothelia, or absent (score 0 ). Heterogeneity of the immunoreactions was recorded, but the predominant pattern was used for the final results.

\section{Results}

PTEN molecular analyses. A total of 42 primary colorectal carcinomas were included in the present study, 19 of which were successfully propagated as subcutaneous xenotransplants in athymic nude mice generated in our laboratory and 3 were available as primary tumour cell lines (subset 1), whereas xenotransplantation had not been attempted/successful for the remaining 20 tumours (subset 2). Clinicopathological features and the molecular data that formed the basis for the molecular classifications of these tumours are provided in Table II. The tumours were grouped according to the criteria set out in Ostwald et al (10). Subset 1 consisted of 5 sporadic high-degree microsatellite instable colorectal carcinomas with extensive and strong methylations that included (and silenced) the MLH1 gene (spMSI-H type), 3 microsatellite stable colorectal carcinomas of the $\mathrm{CpG}$ island methylator phenotype (CIMP-H/non-MSI-H type), and 14 colorectal carcinomas of the sporadic standard type (spSTD type). A similar composition was found for subset 2: 4 tumours were of the spMSI-H type; 2 of the CIMP-H/non-MSI-H type and 14 of the spSTD type.

The results of the molecular analyses of the PTEN gene are summarised in Table III. Sequencing of exons 1 to 9 of the PTEN gene revealed a total of 8 somatic mutations in 5 tumours. Colorectal carcinoma HROC 69 (spSTD, subset 1) harboured three different mutations: one stop mutation at codon 7 (E7*), and 2 point mutations in exon 5 (R130Q and R142Q). Furthermore, a monoallelic point mutation at codon 60 (K60T) was found in HROC 48 (spMSI-H, subset 1), 
Table II. Clinicopathological and molecular characteristics of the tumours included in the present study.

\begin{tabular}{|c|c|c|c|c|c|c|}
\hline \multirow[b]{2}{*}{ Tumour ID (molecular type) } & \multirow[b]{2}{*}{ Histotype (grade) } & \multirow[b]{2}{*}{ TNM } & \multirow[b]{2}{*}{ K-Ras (G12, G13) } & \multirow[b]{2}{*}{ B-Raf (V600E) } & \multicolumn{2}{|c|}{ MethyLight } \\
\hline & & & & & MLH1 & Others $^{\mathrm{a}}$ \\
\hline \multicolumn{7}{|l|}{ Subset 1} \\
\hline HROC 24 (spMSI-H) & $\mathrm{ADC}^{\mathrm{b}}(\mathrm{G} 2)$ & T2N0M0 & $\mathrm{Wt}$ & Mutated & Positive & 5 \\
\hline HROC 48 (spMSI-H) & $\mathrm{ADC}(\mathrm{G} 3)$ & $\mathrm{T} 2 \mathrm{~N} 1 \mathrm{M} 0$ & $\mathrm{Wt}$ & $\mathrm{Wt}$ & Positive & 5 \\
\hline HROC 50 (spMSI-H) & $\mathrm{ADC}(\mathrm{G} 2)$ & T4N0M0 & $\mathrm{Wt}$ & Mutated & Positive & 5 \\
\hline HROC 53 (spMSI-H) & $\mathrm{ADC}(\mathrm{G} 3)$ & T3N0M0 & $\mathrm{Wt}$ & $\mathrm{Wt}$ & Positive & 2 \\
\hline HROC 87 (spMSI-H) & ADC (G3) & T3N0M0 & $\mathrm{Wt}$ & Mutated & Positive & 5 \\
\hline HROC 40 (CIMP-H/non-MSI-H) & ADC (G3) & T3N1M0 & Mutated & $\mathrm{Wt}$ & Negative & 3 \\
\hline HROC 60 (CIMP-H/non-MSI-H) & $\mathrm{ADC}(\mathrm{G} 2)$ & T2N0M0 & $\mathrm{Wt}$ & $\mathrm{Wt}$ & Negative & 4 \\
\hline HROC 54 (CIMP-H/non-MSI-H) & $\mathrm{ADC}(\mathrm{G} 2)$ & T3N2M0 & Mutated & $\mathrm{Wt}$ & Negative & 3 \\
\hline Cell line HROC 18 (spSTD) & $\mathrm{ADC}(\mathrm{G} 2)$ & T2N0M0 & $\mathrm{Wt}$ & $\mathrm{Wt}$ & Negative & 0 \\
\hline HROC 32 (spSTD) & $\mathrm{ADC}(\mathrm{G} 2)$ & $\mathrm{T} 4 \mathrm{~N} 2 \mathrm{M} 0$ & Mutated & Wt & Negative & 0 \\
\hline HROC 39 (spSTD) & ADC (G3) & T4N0M0 & Wt & $\mathrm{Wt}$ & Negative & 1 \\
\hline HROC 46 (spSTD) & ADC (G3) & T3N0M1 & Mutated & $\mathrm{Wt}$ & Negative & 0 \\
\hline HROC 59 (spSTD) & $\mathrm{ADC}(\mathrm{G} 2)$ & T3N1M1 & $\mathrm{Wt}$ & $\mathrm{Wt}$ & Negative & 1 \\
\hline HROC 62 (spSTD) & $\mathrm{ADC}(\mathrm{G} 3)$ & $\mathrm{T} 4 \mathrm{~N} 2 \mathrm{M} 0$ & Mutated & Wt & Negative & 1 \\
\hline HROC 65 (spSTD) & $\mathrm{ADC}(\mathrm{G} 2)$ & T3N2M1 & Mutated & $\mathrm{Wt}$ & Negative & 1 \\
\hline HROC 68 (spSTD) & $\mathrm{ADC}(\mathrm{G} 2)$ & T4N2M1 & Mutated & Wt & Negative & 0 \\
\hline HROC 69 (spSTD) & $\mathrm{ADC}(\mathrm{G} 3)$ & T3N0M0 & $\mathrm{Wt}$ & $\mathrm{Wt}$ & Negative & 1 \\
\hline HROC 70 (spSTD) & $\mathrm{ADC}(\mathrm{G} 2)$ & T4N1M0 & Mutated & $\mathrm{Wt}$ & Negative & 2 \\
\hline HROC 80 (spSTD) & $\mathrm{ADC}(\mathrm{G} 2)$ & $\mathrm{T} 3 \mathrm{~N} 2 \mathrm{M} 0$ & Mutated & $\mathrm{Wt}$ & Negative & 1 \\
\hline Cell line HROC 85 (spSTD) & $\mathrm{ADC}(\mathrm{G} 2)$ & T3N1M0 & Wt & $\mathrm{Wt}$ & Negative & 1 \\
\hline Cell line HROC 86 (spSTD) & ADC (G3) & T3N1M0 & Mutated & $\mathrm{Wt}$ & Negative & 1 \\
\hline HROC 107 (spSTD) & $\mathrm{ADC}(\mathrm{G} 2)$ & T3N2M1 & Mutated & $\mathrm{Wt}$ & Negative & 0 \\
\hline \multicolumn{7}{|l|}{ Subset 2} \\
\hline HROC 21 (spMSI-H) & ADC (G3) & T2N0M0 & Wt & Mutated & Positive & 3 \\
\hline HROC 35 (spMSI-H) & ADC (G3) & T4N1M0 & $\mathrm{Wt}$ & Mutated & Positive & 5 \\
\hline HROC 55 (spMSI-H) & $\mathrm{ADC}(\mathrm{G} 3)$ & T2N0M0 & $\mathrm{Wt}$ & Mutated & Positive & 5 \\
\hline HROC 146 (spMSI-H) & ADC (G3) & T3N0M0 & Wt & Mutated & Positive & 3 \\
\hline HROC 1 (CIMP-H/non-MSI-H) & ADC (G3) & T3N0M0 & Mutated & $\mathrm{Wt}$ & Negative & 5 \\
\hline HROC 30 (CIMP-H/non-MSI-H) & $\mathrm{ADC}(\mathrm{G} 2)$ & T2N0M0 & Mutated & $\mathrm{Wt}$ & Negative & 4 \\
\hline HROC 2 (spSTD) & $\mathrm{ADC}(\mathrm{G} 3)$ & T3N0M0 & Mutated & $\mathrm{Wt}$ & Negative & 1 \\
\hline HROC 3 (spSTD) & $\mathrm{ADC}(\mathrm{G} 1)$ & T3N0M0 & $\mathrm{Wt}$ & $\mathrm{Wt}$ & Negative & 0 \\
\hline HROC 4 (spSTD) & $\mathrm{ADC}(\mathrm{G} 2)$ & T2N0M0 & $\mathrm{Wt}$ & $\mathrm{Wt}$ & Negative & 0 \\
\hline HROC 7 (spSTD) & $\mathrm{ADC}(\mathrm{G} 2)$ & T1N0M0 & Mutated & Wt & Negative & 1 \\
\hline HROC 17 (spSTD) & $\mathrm{ADC}(\mathrm{G} 2)$ & T3N0M0 & $\mathrm{Wt}$ & $\mathrm{Wt}$ & Negative & 2 \\
\hline HROC 26 (spSTD) & ADC (G3) & T4N2M0 & Wt & $\mathrm{Wt}$ & Negative & 2 \\
\hline HROC 52 (spSTD) & $\mathrm{ADC}(\mathrm{G} 2)$ & T2N0M0 & Wt & $\mathrm{Wt}$ & Negative & 1 \\
\hline HROC 64 (spSTD) & $\mathrm{ADC}(\mathrm{G} 2)$ & T2N0M0 & $\mathrm{Wt}$ & $\mathrm{Wt}$ & Negative & 0 \\
\hline HROC 67 (spSTD) & $\mathrm{ADC}(\mathrm{G} 2)$ & T3N1M0 & $\mathrm{Wt}$ & $\mathrm{Wt}$ & Negative & 0 \\
\hline HROC 82 (spSTD) & $\mathrm{ADC}(\mathrm{G} 2)$ & T3N0M0 & $\mathrm{Wt}$ & Wt & Negative & ND \\
\hline HROC 105 (spSTD) & $\mathrm{ADC}(\mathrm{G} 2)$ & T4N2M1 & $\mathrm{Wt}$ & $\mathrm{Wt}$ & Negative & 0 \\
\hline HROC 122 (spSTD) & $\mathrm{ADC}(\mathrm{G} 3)$ & T4N0M0 & $\mathrm{Wt}$ & $\mathrm{Wt}$ & Negative & 0 \\
\hline HROC 125 (spSTD) & $\mathrm{ADC}(\mathrm{G} 2)$ & T3N1M0 & $\mathrm{Wt}$ & $\mathrm{Wt}$ & Negative & 2 \\
\hline HROC 176 (spSTD) & $\mathrm{ADC}(\mathrm{G} 2)$ & T3N2M0 & Mutated & $\mathrm{Wt}$ & Negative & 0 \\
\hline
\end{tabular}

${ }^{a}$ Numbers of the remaining 5 methylation markers other than MLH1 that were positive by MethyLight; badenocarcinoma, not otherwise specified. ADC, adenocarcinoma; wt, wild-type.

and as another monoallelic mutation a frameshift mutation at codon 267 (K267fs*9) was observed in HROC 53 (spMSI-H, subset 1) (Fig. 1). Three mutations were found in two tumours of subset 2: one monallelic point mutation in one tumour $(\mathrm{R} 14 \mathrm{G}$; 
Table III. Results of the molecular and immunohistochemical studies of the PTEN gene.

\begin{tabular}{|c|c|c|c|c|c|c|}
\hline & \multirow[b]{2}{*}{ Mutation } & \multicolumn{3}{|c|}{ Allelotype analyses } & \multirow{2}{*}{$\begin{array}{l}\text { Methylation } \\
\text { (PMR) }\end{array}$} & \multirow{2}{*}{$\begin{array}{c}\text { Immunohisto- } \\
\text { chemistry } \\
\text { (expression) }\end{array}$} \\
\hline & & D10S541 & D10S579 & D10S1765 & & \\
\hline \multicolumn{7}{|l|}{ Subset 1} \\
\hline HROC 24 (spMSI-H) & $\mathrm{Wt}$ & $\mathrm{MSI}^{\mathrm{a}}$ & $0^{\mathrm{b}}$ & MSI & 1 & Retained \\
\hline HROC 48 (spMSI-H) & K60T (new) ${ }^{c}$ & MSI & $\mathrm{LOH}^{\mathrm{d}}$ & MSI & 0 & Retained \\
\hline HROC 50 (spMSI-H) & $\mathrm{Wt}$ & MSI & MSI & N.i. ${ }^{e}$ & 0 & Retained \\
\hline HROC 53 (spMSI-H) & $\mathrm{K} 267 \mathrm{fs} * 9(24 \mathrm{x})$ & MSI & $\mathrm{AI}(0.5)^{\mathrm{f}}$ & MSI & 0 & Reduced/loss \\
\hline HROC 87 (spMSI-H) & $\mathrm{Wt}$ & MSI & 0 & MSI & 0 & Retained \\
\hline HROC 40 (CIMP-H/non-MSI-H) & $\mathrm{Wt}$ & $\mathrm{AI}(0.5)$ & $\mathrm{AI}(0.5)$ & 0 & 0 & Retained \\
\hline HROC 60 (CIMP-H/non-MSI-H) & $\mathrm{Wt}$ & N.i. & 0 & $\mathrm{AI}(0.4)$ & 100 & Retained \\
\hline HROC 54 (CIMP-H/non-MSI-H) & $\mathrm{Wt}$ & 0 & 0 & 0 & 0 & Retained \\
\hline Cell line HROC 18 (spSTD) & $\mathrm{Wt}$ & 0 & 0 & 0 & 0 & Retained \\
\hline HROC 32 (spSTD) & $\mathrm{Wt}$ & $\mathrm{AI}(0.2)$ & N.i. & 0 & 0 & Reduced/loss \\
\hline HROC 39 (spSTD) & $\mathrm{Wt}$ & 0 & N.i. & 0 & 0.7 & Reduced/loss \\
\hline HROC 46 (spSTD) & $\mathrm{Wt}$ & 0 & 0 & 0 & 0 & Reduced/loss \\
\hline HROC 59 (spSTD) & $\mathrm{Wt}$ & $\mathrm{LOH}$ & N.i. & $\mathrm{LOH}$ & 0 & Reduced/loss \\
\hline HROC 62 (spSTD) & $\mathrm{Wt}$ & 0 & N.i. & 0 & 0 & Reduced/loss \\
\hline HROC 65 (spSTD) & $\mathrm{Wt}$ & N.i. & $\mathrm{AI}(2.1)$ & 0 & 0 & Retained \\
\hline HROC 68 (spSTD) & $\mathrm{Wt}$ & $\mathrm{LOH}$ & N.i. & $\mathrm{LOH}$ & 0 & Reduced/loss ${ }^{\mathrm{g}}$ \\
\hline HROC 69 (spSTD) & $\begin{array}{l}\text { E7* }(5 x) \\
\text { R130Q (7x) } \\
\text { R142Q (new) }\end{array}$ & 0 & N.i. & 0 & 0 & Reduced/loss \\
\hline HROC 70 (spSTD) & $\mathrm{Wt}$ & 0 & 0 & 0 & 0 & Reduced/loss \\
\hline HROC 80 (spSTD) & $\mathrm{Wt}$ & 0 & N.i. & 0 & 0 & Retained \\
\hline Cell line HROC 85 (spSTD) & $\mathrm{Wt}$ & 0 & 0 & 0 & ND & Reduced/loss \\
\hline Cell line HROC 86 (spSTD) & $\mathrm{Wt}$ & 0 & 0 & 0 & ND & Retained \\
\hline HROC 107 (spSTD) & $\mathrm{Wt}$ & N.i. & 0 & N.i & 0 & Retained \\
\hline \multicolumn{7}{|l|}{ Subset 2} \\
\hline HROC 21 (spMSI-H) & $\mathrm{Wt}$ & MSI & 0 & 0 & 0 & Retained \\
\hline HROC 35 (spMSI-HI) & $\mathrm{Wt}$ & MSI & $\mathrm{AI}(0.37)$ & 0 & 0 & Retained, strong \\
\hline HROC 55 (spMSI-H) & $\mathrm{Wt}$ & N. ampl. ${ }^{\text {h }}$ & 0 & 0 & 0 & Reduced/loss \\
\hline HROC 146 (spMSI-H) & $\begin{array}{l}\text { K164fs*3 (new) } \\
\text { E288fs*3 (1x) }\end{array}$ & MSI & N.i. & MSI & 0 & Reduced/loss \\
\hline HROC 1 (CIMP-H/non-MSI-H) & $\mathrm{Wt}$ & N. ampl. & 0 & 0 & 0 & Retained \\
\hline HROC 30 CIMP-H/non-MSI-H) & R14G (2x) & 0 & 0 & 0 & 0 & Reduced/loss \\
\hline HROC 2 (spSTD) & $\mathrm{Wt}$ & 0 & 0 & 0 & 0 & Retained, strong \\
\hline HROC 3 (spSTD) & $\mathrm{Wt}$ & N.i. & 0 & 0 & 0 & Retained \\
\hline HROC 4 (spSTD) & $\mathrm{Wt}$ & N. ampl. & 0 & 0 & 0 & Retained \\
\hline HROC 7 (spSTD) & $\mathrm{Wt}$ & 0 & 0 & 0 & 0 & Reduced/loss \\
\hline HROC 17 (spSTD) & $\mathrm{Wt}$ & 0 & 0 & N.i. & 0 & Retained \\
\hline HROC 26 (spSTD) & $\mathrm{Wt}$ & N.i. & 0 & 0 & 0 & Reduced/loss \\
\hline HROC 52 (spSTD) & $\mathrm{Wt}$ & 0 & 0 & 0 & 0 & Retained, strong \\
\hline HROC 64 (spSTD) & $\mathrm{Wt}$ & 0 & 0 & $\mathrm{AI}(0.5)$ & 0 & Retained \\
\hline HROC 67 (spSTD) & $\mathrm{Wt}$ & N.i. & N.i. & N.i. & 0 & $\mathrm{ND}^{\mathrm{i}}$ \\
\hline HROC 82 (spSTD) & $\mathrm{Wt}$ & 0 & N.i. & 0 & 0 & Reduced/loss \\
\hline HROC 105 (spSTD) & $\mathrm{Wt}$ & 0 & N.i. & N.i. & 0 & Retained \\
\hline HROC 122 (spSTD) & $\mathrm{Wt}$ & 0 & N.i. & 0 & 0 & Reduced/loss \\
\hline HROC 125 (spSTD) & $\mathrm{Wt}$ & 0 & 0 & MSI & 0 & Reduced/loss \\
\hline HROC 176 (spSTD) & $\mathrm{Wt}$ & 0 & N.i. & $\mathrm{AI}(2.2)$ & 0 & Retained \\
\hline
\end{tabular}

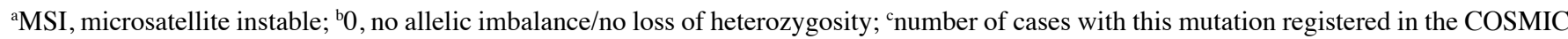
database (filtered for 'large intestine') is given in brackets; ${ }^{\mathrm{d}} \mathrm{LOH}$, loss of heterozygosity, i.e. complete loss of one allele; ${ }^{\mathrm{e}} \mathrm{N}$.i., not informative; ${ }^{\mathrm{f}} \mathrm{AI}$, allelic imbalance, tumour/normal ratio is given in brackets; ${ }^{\mathrm{g} S t r o n g}$ immunostaining of few cells at the invasive margin; ${ }^{\mathrm{h}} \mathrm{N}$. ampl., DNA not amplifiable; ${ }^{\mathrm{N} D}$, no data due to failure to obtain adequate immunostaining of internal controls. PTEN, phosphatase and tensin homologue. 
A HROC 48: K60T

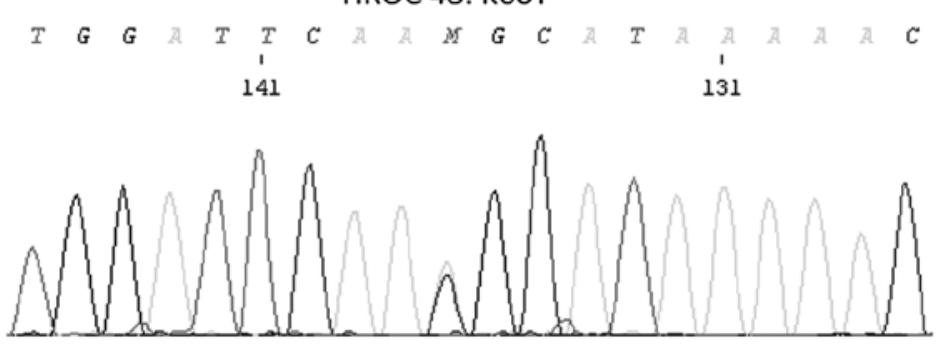

B HROC 146 : K164fs*3
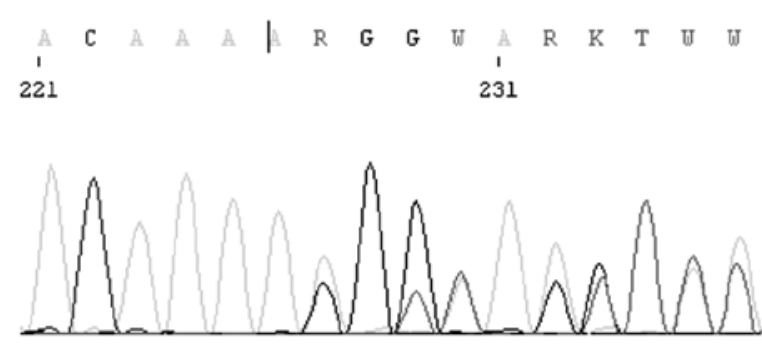

Figure 1. Examples of PTEN gene mutations. (A) K60T found in HROC 48 and (B) K164fs*3 in HROC 146. PTEN, phosphatase and tensin homologue.

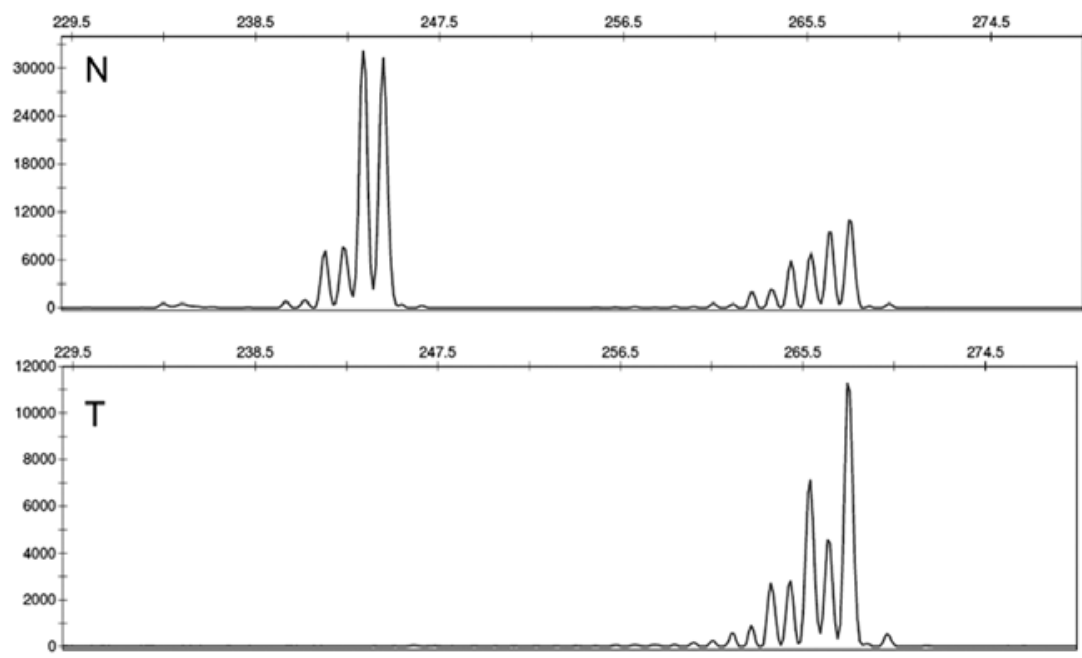

Figure 2. Representative allelotyping electropherogram using D10S541. Note complete loss of one allele in the tumour sample (XHROC 59, lower lane) compared to DNA from normal tissue (upper lane).

HROC 30, CIMP-H/non-MSI-H) and two monoallelic frameshift mutations in another tumour (K164fs*1 and E288fs*1; HROC 146, spMSI-H); to discriminate between monoallelic and biallelic mutations, the DNAs from tumours of subset 2 were from neoplastic glands isolated by laser-capture microdissection.

LOH at the PTEN gene locus 10p23 was addressed with the polymorphic microsatellite markers D10S541, D10S579 and D10S1765. Importantly, in order to be able to demonstrate actual complete loss of one allele, we used DNA extracted from the xenotransplants (subset 1), or DNA from neoplastic glands that had been separated from the stroma by laser-capture microdissections (subset 2). By this approach, we were able to distinguish between $\mathrm{AI}$ and $\mathrm{LOH}$ sensu stricto: complete loss of one allele was noted in 3 tumours (two
spSTD and one spMSI-H, all of subset 1; see Fig. 2 for an exemplary electropherogram). AI was more frequent, as it was found in 8 additional tumours. HROC 48 was the only tumour observed to combine LOH and PTEN gene mutation. Results of the microsatellite marker analyses are documented in detail in Table III.

Quantitative real-time PCR using the MethyLight technology was performed to assay for methylations of $\mathrm{CpGs}$ in the PTEN gene promoter. Strong methylation $(\mathrm{PMR}=100)$ was observed in only 1 case (HROC 60), a colorectal carcinoma of the CIMP-H/non-MSI-H type.

PTEN immunohistochemistry. PTEN immunohistochemistry with $\mathrm{mAb} 6 \mathrm{H} 2.1$ worked reasonably well with the paraffin sections from the archived blocks. Endothelia and, if present, 

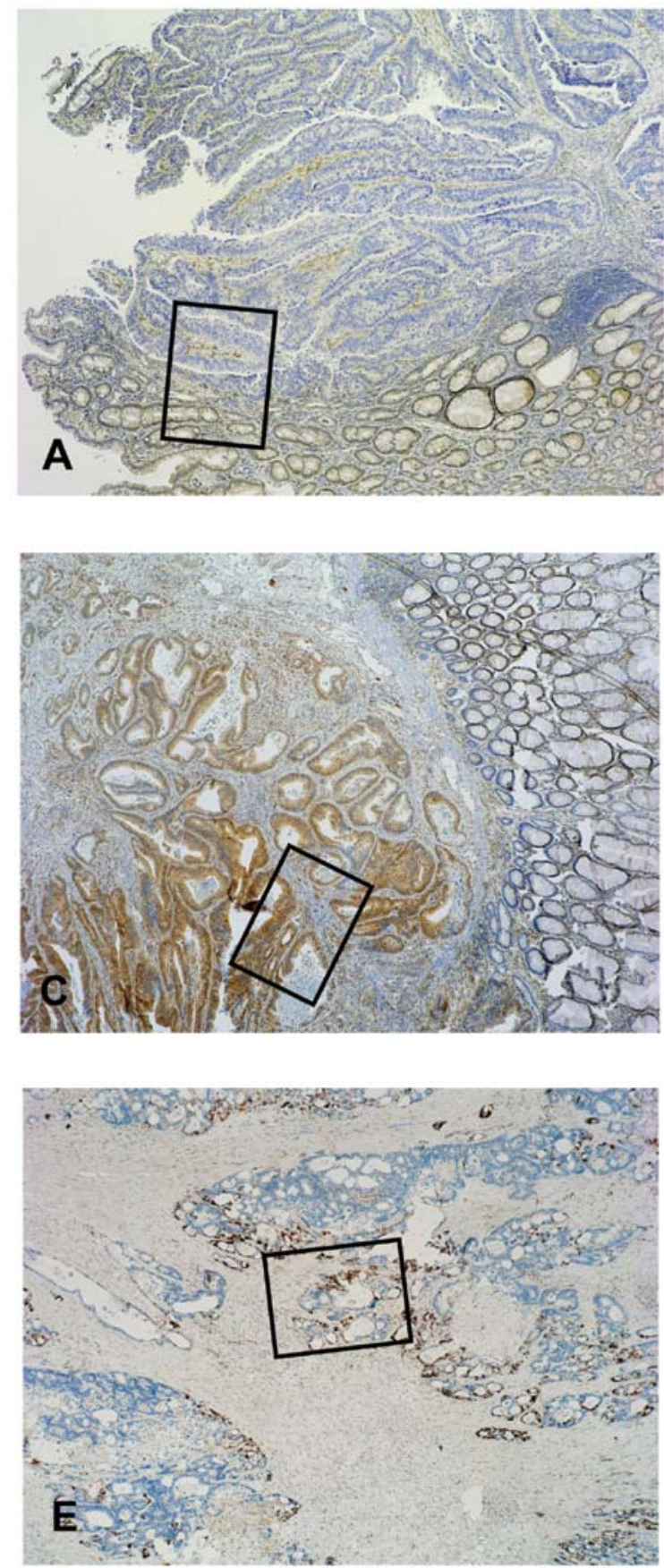
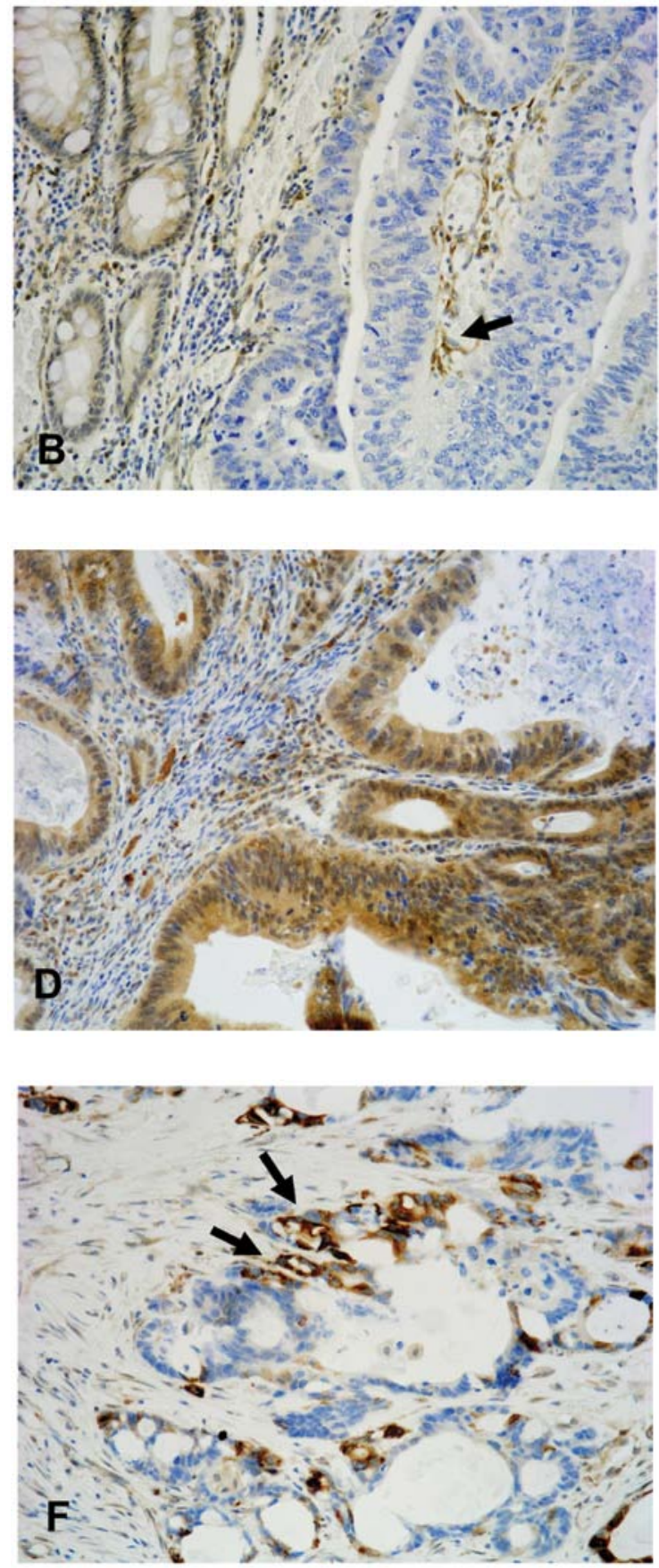

Figure 3. Examples of PTEN immunohistochemistry. (A) Colorectal carcinoma with loss of PTEN expression by immunohistochemistry [x4 objective; boxed area is shown at higher magnification (x20 objective) in B]. Note absence of immunostaining in the cancer whereas immunostaining is noted in normal colonocytes and endothelia (arrow in B). (C) Colorectal carcinoma with strong cytoplasmic and nuclear immunostaining indicating overexpression (x4 objective; boxed area in D by x 20 objective). (E) PTEN immunohistochemistry of HROC 68 ( $\mathrm{x} 4$ objective; boxed area in F by $\mathrm{x} 20$ objective), exhibited an unusual pattern with absence of immunostaining in most of the neoplastic glands but strong cytoplasmic (but not nuclear) immunostaining at the invasive margin (arrows in F). PTEN, phosphatase and tensin homologue.

nerves and colonocytes of the adjacent normal mucosa conveniently provided internal controls of the immunoreactions and a standard for the evaluations. Strong immunostaining of the nuclei and the cytoplasm of endothelia was noted without heterogeneity in all sections. Immunostaining of colonocytes was weaker; the former was taken as the standard for score 2, the latter for score 1 . In most cases, although convincingly specific, PTEN immunostaining was fairly weak in the cytoplasm and/or nuclei of tumour cells. Furthermore, it was somewhat heterogeneous in several of the cases; however, regional differences did not exceed one score-point, and the final classification was made according to the dominant pattern. By this approach, 18 tumours were observed to have reduced or loss of PTEN expression, and retention of PTEN expression (i.e. immunostaining similar to colonocytes) was recorded for 20 tumours (one tumour was not amenable to immunostaining for technical reasons). Overexpression was noted in 3 cases only. Representative images of PTEN immunohistochemistry are provided in Fig. 3, and the results are summarised in Table III. Importantly, in a single case 
(HROC 68, subset 1, spSTD) strong immunostaining of the cytoplasm (cytoplasmic score 2) was observed neatly restricted to a minority of tumour cells at the invasive margin (Fig. 3) while the bulk of the tumour had lost PTEN expression. As far as we are aware, this pattern of PTEN immunohistochemistry has not been previously reported.

\section{Discussion}

The numbers of PTEN gene mutations in the present study align quite well with the published data; in the COSMIC database 349 mutations were reported for 2,807 colorectal carcinomas analyzed (12.4\%) while we found mutations in 5 of 42 colorectal carcinomas (11.9\%). Five mutations from the present study are on record in the COSMIC database but 3 have not previously been reported (annotated in Table III). Similar to published series $(4,13)$, we observed that mutations were more frequent among colorectal carcinomas with microsatellite instability ( 3 of the 9 spMSI-H in this series). This is well explained by the incapacity for mismatch repair that causes microsatellite instability, including insertions/deletions in nucleotide repeats that are frequent in downstream coding regions of the PTEN gene.

However, the present study was not limited to mutational analyses. Specifically, we addressed whether molecular aberrations of the PTEN gene found in a series of colorectal carcinoma that encompassed the major molecular types would fit with its universally presumed role of a tumoursuppressor gene. As far as we are aware, this is the only study of colorectal carcinoma using DNA from tumour cells isolated from the stroma to which simultaneously allelotyping and mutational as well as methylation analysis were applied, allowing a synoptic assessment. While PTEN gene mutations and complete loss of one allele (i.e. LOH sensu stricto) of the PTEN gene were observed in 5 and 3 tumours, respectively, a combination of mutation and $\mathrm{LOH}$ was found in one of the tumours only (HROC 48), and the mutation was missense. This largely contradicts what would be expected of a tumoursuppressor gene in the classical sense, where gene function is lost by an inactivating (often truncating) mutation of one allele, and loss of the genomic material that harbours the other allele. Another tumour in our series, however, was observed to have mutations of both alleles (one truncating and two missense), a constellation that may be taken to emulate the classic combination.

Our observation of only 3 cases of PTEN LOH in a total of 42 tumours analyzed $(7.1 \%)$ is considerably lower than the $19.0-34.7 \%$ reported in other studies $(12,13,15)$. However, it must be remembered that the usual technique of using DNA from whole tumour homogenates includes DNA from stromal cells, thus considerably contaminating the 'tumour' DNA with normal DNA. To circumvent this potential source of error, we used tumour DNA derived from low-passage xenografts or from neoplastic glands of primaries that were isolated from the stroma by laser-capture microdissection. Accordingly, so-called LOH in other studies in the majority of cases amounts to what in our study was scored as allelic imbalance (AI); this was found in 8 additional tumours. Thus, apparently the majority of so-called PTEN LOHs reported in the literature 'ever since Knudson' (5) may well be spurious and not play a role functionally, particularly not as one of the 'hits' of a tumour-suppressor gene mechanism involving the PTEN gene. The reason for AI is well explained when taking into account the results from a different methodological approach; some of our xenotransplants have previously been analyzed by single-nucleotide polymorphism (SNP)-arrays [HROCs 18, 32, 39, 40, 46, 59, 60, 80; published in (16)]. These investigations showed that the AI is in fact the result of unbalanced large-scale genomic amplification (trisomy 10 or p-arm amplification).

To address whether alternatively PTEN gene silencing may play a role, we also assayed promoter methylation. This was carried out by real-time PCR [MethyLight technology, (11)], a quantitative approach that, as opposed to methylation-specific PCR, allows an objective and functionally meaningful classification of cases. While other CpG loci tested for the molecular classification of our tumours frequently had strong methylations (Table II), PTEN gene promoter methylation was noted in only one case, not combined with mutation or LOH. The results from our series, therefore, do not provide evidence that PTEN in colorectal carcinoma may function as an 'epi-driver' gene instead of as a tumour-suppressor gene in the classical sense.

PTEN expression in our tumours was studied by immunohistochemistry using the monoclonal antibody $6 \mathrm{H} 2.1$. This antibody's specificity has been shown in previous studies of colorectal carcinoma $(13,14)$. By immunohistochemistry, reduction or loss of PTEN expression was a frequent event, noted in 18 of the 41 tumours amenable to this study (43.9\%). Considering the well-established function of PTEN in cell cycle control and cell migration, this observation points to a definite role of PTEN in colorectal carcinoma tumour biology, although apparently by mechanisms different from what is usually meant when referring to PTEN as a tumour-suppressor gene; the most plausible mechanism to explain reduction or even loss of PTEN expression in colorectal carcinoma cells at this juncture is (dys)regulation by unknown factors from the microenvironment that act on the tumour cells. This hypothetical explanation also allows for plasticity, i.e. it can explain fluctuations in downregulation and re-expression, and thus accounts for the somewhat inhomogenous patterns of expression observed by immunohistochemistry in many of the cases; in fact, the unusual very focal overexpression at the invasive margin noted in one of our tumours (HROC 68, Fig. 3) would be difficult to explain if PTEN were thought to be compromised by genetic defects.

Reduced PTEN expression has been reported as a negative predictor for EGF-R blocking agents such as cetuximab or panitumumab in the setting of metastasizing colorectal carcinoma $(17,18)$, underscoring its functional importance. Given the difficulties that surgical pathologists usually encounter when trying to adapt quantitative/semi-quantitative immunohistochemistry for routine use, testing the gene by molecular pathology instead would have been desirable; but alterations of PTEN gene expression are not appreciably mirrored in genomic aberrations, precluding this approach.

We conclude that downregulation of the PTEN gene is frequent in colorectal carcinoma, and is likely to have a functional role. However, two hits on the PTEN gene, by mutation and $\mathrm{LOH}$ or epigenetic silencing, respectively, is a rare event. 


\section{Acknowledgements}

This study was substantially supported by grant no. 108919 from the Deutsche Krebshilfe (http://www.northgermantumorbank-crc.de).

\section{References}

1. Wood LD, Parsons DW, Jones S, et al: The genomic landscapes of human breast and colorectal cancers. Science 318: 1108-1113, 2007.

2. Planchon SM, Waite KA and Eng C: The nuclear affairs of PTEN. J Cell Sci 121: 249-253, 2008.

3. Steck PA, Pershouse MA, Jasser SA, et al: Identification of a candidate tumour suppressor gene, $M M A C l$, at chromosome $10 \mathrm{q} 23.3$ that is mutated in multiple advanced cancers. Nat Genet 15: 356-362, 1997.

4. Shin KH, Park YJ and Park JG: PTEN mutations in colorectal cancers displaying microsatellite instability. Cancer Lett 174 189-194, 2001.

5. Devilee P, Cleton-Jansen AM and Cornelisse CJ: Ever since Knudson. Trends Genet 17: 569-573, 2001.

6. Vogelstein B, Papadopoulos N, Velculescu V, Zhou S, Diaz LA Jr and Kinzler KW: Cancer genome landscapes. Science 339: 1546-1558, 2013.

7. Goel A, Arnold CN, Niedzwiecki D, et al: Frequent inactivation of PTEN by promoter hypermethylation in microsatellite instability-high sporadic colorectal cancers. Cancer Res 64 3214-3221, 2004

8. Oberländer M, Linnebacher M, König A, et al: The 'North German Tumor Bank of Colorectal Cancer': status report after the first 2 years of support by the German Cancer Aid Foundation. Langenbecks Arch Surg 398: 251-258, 2013.

9. Linnebacher M, Maletzki C, Ostwald C, Klier U, Krohn M, Klar E and Prall F: Cryopreservation of human colorectal carcinomas prior to xenografting. BMC Cancer 10: 362, 2010.
10. Ostwald C, Linnebacher M, Weirich V and Prall F: Chromosomally and microsatellite stable colorectal carcinomas without the $\mathrm{CpG}$ island methylator phenotype in a molecular classification. Int J Oncol 35: 321-327, 2009.

11. Ogino S, Cantor M, Kawasaki T, Brahmandam M, Kirkner GJ, Weisenberger DJ, Campan M, et al: $\mathrm{CpG}$ island methylator phenotype (CIMP) of colorectal cancer is best characterised by quantitative DNA methylation analysis and prospective cohort studies. Gut 55: 1000-1006, 2006.

12. Nassif NT, Lobo GP, Wu X, Henderson CJ, Morrison CD, Eng C, Jalaludin B and Segelov E: PTEN mutations are common in sporadic microsatellite stable colorectal cancer. Oncogene 23: 617-628, 2004.

13. Zhou XP, Loukola A, Salovaara R, Nystrom-Lahti M, Peltomäki P, de la Chapelle A, Aaltonen LA and Eng C: PTEN mutational spectra, expression levels, and subcellular localization in microsatellite stable and unstable colorectal cancers. Am J Pathol 161: 439-447, 2002.

14. Perren A, Weng LP, Boag AH, et al: Immunohistochemical evidence of loss of PTEN expression in primary ductal adenocarcinomas of the breast. Am J Pathol 155: 1253-1260, 1999.

15. Garcia JM, Rodriguez R, Silva J, et al: Intratumoral heterogeneity in microsatellite alterations in BRCA1 and PTEN regions in sporadic colorectal cancer. Ann Surg Oncol 10: 876-881, 2003.

16. Linnebacher M, Ostwald C, Koczan D, et al: Single nucleotide polymorphism array analysis of microsatellite-stable, diploid/ near-diploid colorectal carcinomas without the $\mathrm{CpG}$ island methylator phenotype. Oncol Lett 5: 173-178, 2013.

17. Perrone F, Lampis A, Orsenigo M, et al: PIK3CA/PTEN deregulation contributes to impaired responses to cetuximab in metatatic colorectal cancer patients. Ann Oncol 20: 84-90, 2009.

18. Razis E, Briasoulis E, Vrettou E, et al: Potential value of PTEN in predicting cetuximab response in colorectal cancer: an exploratory study. BMC Cancer 8: 234, 2008. 